Check for updates

New York

Cite this as: BMJ 2021;373:n1204 http://dx.doi.org/10.1136/bmj.n1204 Published: 11 May 2021

\title{
Covid-19: FDA authorises Pfizer vaccine for children 12-15
}

\section{Janice Hopkins Tanne}

US public health experts are to meet this week to decide how to use the Pfizer BioNTech vaccine in adolescents after the Food and Drug Administration (FDA) granted it emergency use authorisation (EUA) for children aged 12-15. ${ }^{1}$

The Pfizer BioNTech vaccine, like Moderna's, already has EUA for administration to people over the age of 16. Both Moderna and Johnson \& Johnson, which make the other two vaccines approved in the US, are testing their vaccines in children.

About 1.5 million young people aged 11 to 17 have had covid-19 in the past year and 300 people under 18 have died, according to the Centers for Disease Control and Prevention. Although adolescents usually have a milder disease than adults, they can spread the infection.

Janet Woodcock, FDA's acting commissioner, said that expanding Pfizer's EUA to include adolescents "is a significant step in the fight against the pandemic, bringing us closer to returning to a sense of normalcy." She assured parents and the public that FDA had taken "a rigorous and thorough review of all available data."

Vaccination of adolescents should make it easier for schools to reopen.

Some 2260 children were enrolled in a randomised, placebo controlled clinical trial in the US, the FDA said. Side effects were like those seen in adults-pain at the injection site, tiredness, headache, chills, muscle pain, fever, and joint pain. Their immune response was at least as good as that of participants aged 16 to 25 .

"Vaccinating children for covid-19 is a key component for reaching the two thirds threshold herd immunity and stop the pandemic from continuing to spread and mutate," said Miguela Caniza, director of the infectious diseases programme at St Jude Children's Research Hospital in Memphis, Tennessee.

She pointed out that "children and teenagers are a highly mobile population attending schools, sports, extracurricular activities, and intersecting more often with various age groups including caretakers and older family members.” Because a high percentage are asymptomatic or have mild symptoms if they are infected they may spread the disease, especially if they don't take precautions-masking, distancing, frequent hand washing. ${ }^{2}$

The Pfizer BioNTech vaccine will be given in the same dosage and schedule as for adults-two doses, three weeks apart.

Vaccination of adults has slowed in the US, partly because of hesitancy, and there is an excess of vaccines in many states. As of 10 May about $35 \%$ of the US population, or about 115 million people, has been fully vaccinated and about 46\%, or about 153 million people, have received one dose. The US, with a population of about 330 million, has experienced 32.5 million cases and about 579 ooo deaths from covid-19, ${ }^{34}$ although these numbers are thought to be an undercount.

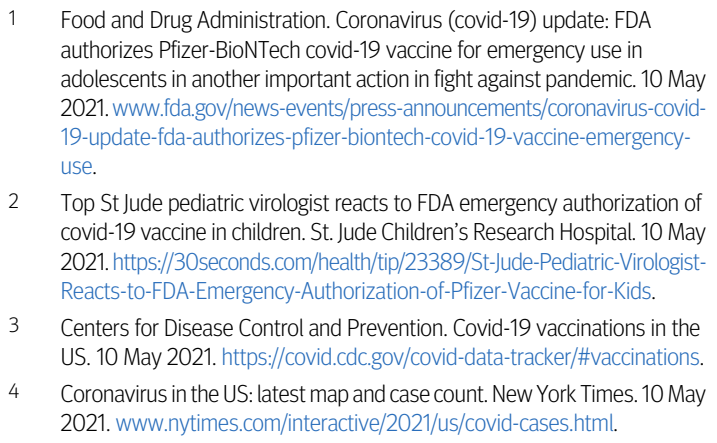

Food and Drug Administration. Coronavirus (covid-19) update: FDA authorizes Pfizer-BioNTech covid-19 vaccine for emergency use in adolescents in another important action in fight against pandemic. 10 May 2021. www.fda.gov/news-events/press-announcements/coronavirus-covid19-update-fda-authorizes-pfizer-biontech-covid-19-vaccine-emergencyuse.

2 Top St Jude pediatric virologist reacts to FDA emergency authorization of covid-19 vaccine in children. St. Jude Children's Research Hospital. 10 May 2021. https://30seconds.com/health/tip/23389/St-Jude-Pediatric-VirologistReacts-to-FDA-Emergency-Authorization-of-Pfizer-Vaccine-for-Kids.

3 Centers for Disease Control and Prevention. Covid-19 vaccinations in the US. 10 May 2021. https://covid.cdc.gov/covid-data-tracker/\#vaccinations.

4 Coronavirus in the US: latest map and case count. New York Times. 10 May 2021. www.nytimes.com/interactive/2021/us/covid-cases.html.

This article is made freely available for use in accordance with BMJ's website terms and conditions for the duration of the covid-19 pandemic or until otherwise determined by BMJ. You may use, download and print the article for any lawful, non-commercial purpose (including text and data mining) provided that all copyright notices and trade marks are retained. 